\title{
Review on strategies for biofouling mitigation in spiral wound membrane systems
}

Szilárd Bucs ${ }^{\mathrm{a}}$, Nadia Farhat ${ }^{\mathrm{a}}$, Joop C. Kruithof ${ }^{\mathrm{b}}$, Cristian Picioreanu ${ }^{\mathrm{c}}$, Mark C.M. van Loosdrecht $^{\mathrm{c}}$, Johannes S. Vrouwenvelder ${ }^{\mathrm{a}, \mathrm{c}}$

${ }^{\text {a}}$ Water Desalination and Reuse Center, Division of Biological and Environmental Science and Engineering, King Abdullah University of Science and Technology, Thuwal 23955-6900,

Saudi Arabia. (Szilard.Bucs@kaust.edu.sa; Nadia.Farhat@kaust.edu.sa

;Johannes.Vrouwenvelder@kaust.edu.sa)

${ }^{\text {b} W e t s u s, ~ E u r o p e a n ~ C e n t r e ~ o f ~ E x c e l l e n c e ~ f o r ~ S u s t a i n a b l e ~ W a t e r ~ T e c h n o l o g y, ~ O o s t e r g o w e g ~ 9, ~}$ 8911 MA Leeuwarden, The Netherlands. (Joop.Kruithof@wetsus.nl)

'Department of Biotechnology, Faculty of Applied Sciences, Delft University of Technology, Van der Maasweg 9, 2629 HZ Delft, The Netherlands. (C.Picioreanu@tudelft.nl;

M.C.M.vanLoosdrecht@tudelft.nl; J.S.Vrouwenvelder@tudelft.nl) 


\begin{abstract}
Because of the uneven distribution of fresh water in time and space, a large number of regions are experiencing water scarcity and stress. Membrane based desalination technologies have the potential to solve the fresh water crisis in coastal areas. However, in many cases membrane performance is restricted by biofouling. The objective of this review is to provide an overview on the state of the art strategies to control biofouling in spiral wound reverse osmosis membrane systems and point to possible future research directions. A critical review on biofouling control strategies such as feed water pre-treatment, membrane surface modification, feed spacer geometry optimization and hydrodynamics in spiral wound membrane systems is presented. In conclusion, biofouling cannot be avoided in the long run, and thus biofouling control strategies should focus on delaying the biofilm formation, reducing its impact on membrane performance and enhancing biofilm removal by advanced cleaning strategies. Therefore, future studies should aim on: (i) biofilm structural characterization; (ii) understanding to what extent biofilm properties affect membrane filtration performance, and (iii) developing methods to engineer biofilm properties such that biofouling would have only a low or delayed impact on the filtration process and accumulated biomass can be easily removed.
\end{abstract}




\section{Introduction}

Currently, more than two billion people live in highly water-stressed areas (UNDP, 2006; Vörösmarty et al., 2000). Because of the uneven distribution of fresh water in time and space, the situation is likely to worsen in the future as a large number of regions are expected to experience more extreme climate conditions and rapidly growing demands in water-use sectors: agriculture (crop production, livestock), domestic (municipal), and industry (energy, manufacturing) (Vörösmarty et al., 2000).

Since more than 97 percent of the water in the world is seawater, desalination technologies have the potential to solve the fresh water crisis. Seawater desalination is already used in many countries mainly in water scarce regions such as the Middle East, as well as in countries with adequate freshwater resources.

Desalination technologies can be divided into two major groups: thermal and membrane desalination. While thermal desalination was the main technology in the past, membrane-based desalination technologies gained importance in the last decade, reaching 60 percent of the global desalination capacity in 2015 with a continuously increasing trend (Pankratz, 2012). This is caused by the improved efficiency and lower energy demand of the membrane-based desalination processes, lowering thus the cost of water production. Reverse osmosis (RO) and nanofiltration (NF) membrane systems currently hold the largest desalination capacity globally (Lattemann et al., 2010). Besides RO and NF there are also alternative emerging membranebased desalination processes including electrodialysis (ED), membrane distillation (MD) and forward osmosis (FO).

Osmosis is the naturally occurring process where the water from solution passes through a semipermeable membrane to dilute a more concentrated solution. Reverse osmosis (RO) applies hydraulic pressure on the concentrated solution so that the water transport through the membrane is reversed and fresh water can be separated from saline water. RO membranes are able to reject colloidal and dissolved matter from aqueous solutions, resulting in a more concentrated solution called "brine" and fresh water, usually referred as "permeate".

Commercially available membrane modules include spiral-wound, hollow fibre, tubular and modules (Mulder, 1996). Amongst these, spiral wound modules are most commonly applied, due to their high membrane area to volume ratio. The major components of a spiral-wound module are the membrane, the feed and permeate channels, spacers keeping the membrane leaves apart, the permeate tube and the membrane housing (Dickson et al., 1994). The feed 
channel spacer may enhance mass transfer near the membrane, but inevitably increases pressure loss along the membrane leaf (Da Costa et al., 1994; Radu et al., 2010). Membrane sheets with spacers in between are glued together on three sides to form an envelope and multiple envelopes are attached to and rolled up around the permeate tube to create the feed and permeate channels. A pressurized membrane module housing holds the membrane leaves in place. Usually, three or more modules are connected in series in a pressure vessel (Schwinge et al., 2004).

The performance of the modules is affected by many factors: (i) spacers geometry, which greatly affects local mixing, mass transfer (concentration polarization) and pressure loss, (ii) fouling propensity and cleaning ability, (iii) plant design and operating conditions, such as feed pre-treatment, feed concentration, feed pressure and permeate recovery.

Four major types of fouling can occur in spiral wound membrane systems: colloidal (suspended particles such as silica), inorganic (salt precipitates such as metal hydroxides and carbonates causing scale formation), organic (natural organic matters such as humic acids), and biological (such as bacteria and fungi). Because the reverse osmosis membranes are nonporous, the formation of a fouling layer on the membrane surface is the dominant fouling mechanism (Kang and Cao, 2012). RO membrane fouling is closely related to the interaction between the membrane surface and the foulant. Previous studies indicated that the physicochemical properties of the RO membrane surface, such as hydrophilicity, roughness, and surface charge, and the feed spacer geometry are major factors influencing membrane fouling (Louie et al., 2011; Vrouwenvelder et al., 2009a).

Biofouling is considered the major fouling type of the membrane process because microorganisms can multiply over time. Even if $99.9 \%$ of microorganisms are removed with pre-treatment of the feed water, there are still enough microbial cells remaining to grow by utilizing biodegradable substances in the membrane installation feed water (Flemming, 1997). Biofouling can be considered as a biotic form of organic fouling while fouling caused by organic matter derived from microbial cellular debris can be considered as an abiotic form of biofouling (Flemming, 2002). Biofouling has been known as a contributing factor to more than 45 percent of all membrane fouling (Nguyen et al., 2012) and has been reported as a major problem in nanofiltration (NF) and reverse osmosis (RO) membrane filtration (Flemming, 1997; Nguyen et al., 2012).

Biofouling of the RO membrane results in a decline in permeate water flux and a decrease of salt rejection. The decline in membrane performance it is due to the increase in the hydraulic 
resistance and the trans-membrane osmotic pressure of the fouled membrane. The increase in the trans-membrane osmotic pressure it is the result of bacterial cells deposition, which enhance the concentration polarization of salt near the membrane surface (Herzberg and Elimelech, 2007; Radu et al., 2015). The greatest effect of biofilms on membrane systems may be attributed to the physical properties of the extracellular polymeric substance (EPS) matrix produced by the embedded microorganisms by increasing the hydraulic resistance and thus reducing permeate production.

Several fouling control strategies have been developed and tested in full-scale membrane installations. Colloidal, inorganic and organic fouling can generally be controlled by pretreatment or by dosage of chemicals (e.g. antiscalants). However, biofouling can only be restricted and delayed by pre-treatment, but not eliminated (Bucs et al., 2014b). Direct dosage of oxidizing biocides such as free chlorine is not possible due to damage of the membrane structure causing reduced membrane performance. Several non-oxidizing biocides would be used as nutrient by the microorganisms, thus enhancing biofilm growth (Creber et al., 2010; Vrouwenvelder et al., 2000). Current research is focused on membrane surface modification, non-oxidizing biocides application and modification of the feed channel geometry and operating condition in order to reduce the biofouling in spiral wound membrane systems (Bertheas et al., 2009; Bucs et al., 2015; Cornelissen et al., 2007; Geraldes et al., 2003; Siddiqui et al., 2016; Tang et al., 2009; Wang et al., 2012). Quorum sensing is another approach for biofouling control, aiming at biofilm dispersal in response to certain biochemical compounds; however, no application has been implemented in practice (Dobretsov et al., 2009). Despite the efforts on controlling fouling in spiral wound membrane systems, biofouling remains the major problem in membrane filtration processes, causing increased energy demand and unreliable water production. It is therefore crucial to gain more fundamental understanding of the biofilm formation in spiral wound membrane systems, in order to develop strategies to control and keep biofouling at an acceptable level. If biofouling cannot be avoided in the long run, biofouling control strategies should focus on delaying biofilm formation, reducing its impact on membrane performance and removing biofilms by advanced cleaning strategies.

The objective of this review is to provide an overview on the state of the art strategies to control biofouling in spiral wound reverse osmosis membrane systems and point to possible future research directions.

\section{Biofouling control strategies}


Biofouling is considered the major fouling problem in membrane systems for water treatment. In spite of extensive research to prevent and eliminate biofouling, no successful control strategy has been developed yet. Most common biofouling control strategies are: (i) feed water pretreatment, (ii) membrane surface modification, (iii) feed spacer design and (iv) chemical/mechanical membrane cleaning.

\subsection{Pre-treatment by water filtration and bacterial inactivation}

For a constant and reliable operation of reverse osmosis membrane systems good quality feed water is essential. Good feed water quality is defined by the membrane manufacturers as water with a turbidity lower than one Nephelometric Turbidity Unit, NTU, silt density index SDI $<3$ (or SDI<4), oil and grease $<1 \mathrm{mg} \cdot \mathrm{L}^{-1}$ (Alawadhi, 1997). When the source water does not meet these criteria, the feed water has to be pre-treated before entering the reverse osmosis membrane system. Most commonly applied pre-treatment technologies are based on water filtration (e.g., filtration over granular media and low pressure membrane filtration) and disinfection.

Filtration over granular materials can be categorized into single, dual and mixed media filtration (Prihasto et al., 2009), meaning that one or more materials can form the filter bed. The most important filtration mechanism here is deposition of the suspended particles to filter media grains, as the raw water passes through the filter bed. The most commonly used filter media are sand and anthracite (Chua et al., 2003). Furthermore, to protect the reverse osmosis systems from particle fouling, cartridge filters with a pore size range between 1 and $20 \mu \mathrm{m}$ are applied after the media filter (Alawadhi, 1997).

Low pressure membrane filtration such as microfiltration (MF) and ultrafiltration (UF) has gained importance in the past years as pre-treatment for reverse osmosis systems. Although MF and UF pre-treatment removes very well the bacterial cells from the feed water, biodegradable nutrients can pass UF membranes enabling eventual microbial growth in the subsequent RO installation.

In some cases, activated carbon or biofiltration is used to remove dissolved organic matter from the feed water. Activated carbon adsorption, either in granular or powder form, has also been considered as a feasible mean for reducing membrane fouling, either alone or in combination with other pre-treatment processes (Gur-Reznik et al., 2008; Meier and Melin, 2005; Zhao and $\mathrm{Yu}, 2015)$. Chinu et al., (2009) delayed fouling development in a lab scale setup by using biofiltration as pre-treatment using real seawater. 
To protect the reverse osmosis membranes from biological fouling the raw water is usually disinfected by addition strong oxidant, such as chlorine, monochloramine, hypochlorite, chlorine dioxide, ozone, or UV irradiation.

In case of addition of chemical oxidants such as chlorine a further step is required. Since the reverse osmosis membranes are not resistant to oxidants, residual chlorine has to be removed from the raw water prior to entering the RO membrane system, commonly achieved by dosage of sodium bisulphite or by activated carbon filtration (Prihasto et al., 2009).

Oxidation of organic compounds by addition of ozone has been used as pre-treatment for spiral wound membrane systems. Ozone reacts with the hydrophobic parts of organic foulants and transforms into more hydrophilic groups (Van Geluwe et al., 2011; Yu et al., 2016).

Even with extensive pre-treatment, a very low amount of biodegradable nutrients can be found in the feed water of the RO installation. With the large amount of water provided per membrane surface per day, even minimal amounts of substrate (microgram per litre level) in the feed water lead to a significant organic substrate supply for biofilm growth, which will occur over weeks or months of operation.

Non-oxidising biocides can be used as an effective control biofouling control strategy. An alternative non-oxidising biocide, monochloramine 2,2-dibromo-3-nitrilopropionamide (DBNPA) has been applied in limited number of water treatment plants. DBNPA is rapidly degrading in alkaline aqueous solutions and is compatible with polyamide based membranes and shows high rejection rates for RO membranes (Bertheas et al., 2009). The antimicrobial effect is due to the fast reaction between DBNPA and sulfur-containing organic molecules in microorganisms such as glutathione or cysteine. Siddiqui et al., (2017b), found that DBNPA can be successfully applied to prevent biofouling when it is continuously dosed, however it was not effective as cleaning agent on fouled membranes. Dosage of DBNPA to a biofouled membrane system inactivated the accumulated biomass but did not restore the original membrane performance (Siddiqui et al., 2017b).

\subsection{Membrane modification}

Physical properties (e.g., hydrophilicity, surface charge, roughness) of the membrane surface impact membrane biofouling (Louie et al., 2011, 2006). It is generally accepted that hydrophilic membranes are more resistant to fouling (Kang and Cao, 2012). Deposition of foulant is less likely on neutrally or close to neutrally charged membrane surfaces (Kang and Cao, 2012; Kim and Lee, 2006). Also surface morphology plays a significant role on membrane biofouling, 
because foulant are more likely to be trapped by rougher topologies than by the smoother ones (Louie et al., 2006; Sagle et al., 2009). Many studies showed that, compared to uncoated membranes, less fouling developed when membranes surfaces had a hydrophilic coating (Araújo et al., 2012; Hadidi and Zydney, 2014; Matin et al., 2014; Ostuni et al., 2001; Tang et al., 2009; Venault et al., 2014; Zhao et al., 2007, 2010; Zhu et al., 2009).

In many investigations, only short-term (2-6 h) static protein or bacterial cell (pure strain) adhesion tests were performed (Adout et al., 2010; Miller et al., 2012; Park et al., 2006; Yi et al., 2010). In some other cases, short-term (2-24 h) cross-flow or dead-end filtration tests were used to evaluate the impact of the coating on fouling layer accumulation (Asatekin et al., 2009; Madaeni and Ghaemi, 2007; Sagle et al., 2009; Wang et al., 2012; Zhao et al., 2013). Shortterm studies provide insight into initial protein or bacterial cell attachment to the membrane, but do not predict long term biofilm development (Asatekin et al., 2009; Matin et al., 2014; Miller et al., 2012; van Loosdrecht et al., 1989). Therefore, long-term studies (i.e., several months) are needed to investigate the effective impact of membrane surface modification on biofouling development. It has also been shown experimentally that long-term biofouling studies are more representative for practice than short-term protein and bacterial adhesion tests (Bucs et al., 2017; Louie et al., 2011; Miller et al., 2012).

Few studies investigating coated membranes to control fouling reported on the coating stability (Brzozowska et al., 2011; Bucs et al., 2017; Louie et al., 2006; Ronen et al., 2015). Brzozowska et al. (2011) reported a weak attachment of polymer brushes to the membrane surface, with the coating layer easily removed by the water flow. Experiments with silver nanoparticle-coated feed spacers showed silver leaching during a fouling study using a flow cell (Yang et al., 2009). Louie et al. (2006) investigated the antifouling performance of a polyether-polyamide block copolymer coating on the membrane surface. At the end of a 106 days experimental period with oil/surfactant/water emulsion the presence of the polyether-polyamide coating was shown, meaning that the coating was not removed from the membrane surface during operation. In spite of many studies reporting anti-biofouling effects of various coatings, currently no coating has been developed that can prevent biofouling in membrane systems. Coated membranes can contribute to a delay in biofilm formation, but cannot prevent biofouling.

\subsection{Feed spacer and hydrodynamics}

Feed spacers are used in reverse osmosis membrane modules to keep the membrane sheets apart and to enhance mixing of the feed water thus reducing concentration polarization in the vicinity of the membrane. Extensive research was conducted to optimize the feed spacer geometries to 
reduce concentration polarization. Koutsou et al., $(2009,2007)$ and Koutsou and Karabelas (2010, 2015) determined optimal ratios between the feed spacer filament distance and filament diameter, mean flow angle and angle between filaments. It was shown feed spacers with a mesh angle of $60^{\circ}$, has the highest water flux, however, the associated pressure drops are slightly higher compared to nonwoven geometries. Middle layer geometries with a mesh angle of $30^{\circ}$ produce the lowest water flux, while feed spacers with a mesh angle of $90^{\circ}$ show the lowest pressure drop among all the filament arrangements (Amokrane et al., 2015; Gu et al., 2017; Koutsou and Karabelas, 2010).

Besides the impact on the hydrodynamics, it was shown that feed spacers provide a surface for initial deposition of biofouling that accumulates and eventually spreads to the free membrane area (Baker et al., 1995). Tran et al. (2007) reported that the membrane area in the vicinity of the feed spacer filaments is mostly affected by fouling. It was also shown that the impact of biofouling on the pressure drop was higher in the presence of a feed spacer (Bucs et al., 2014a; Vrouwenvelder et al., 2009b). Therefore, feed spacers are important for membrane performance by affecting the concentration polarization and biofouling. Siddiqui et al., (2016) tested novel $3 \mathrm{D}$ printed feed spacer and showed that by changing the geometry of the feed spacer the impact of biofouling on membrane performance can be reduced. Further optimization of the feed spacer geometry, not only for enhanced mass transfer but also to reduce the impact of biofouling on the process performance, may be possible. Another important aspect of spacer design would be to enable the easy removal of biomass from membrane modules during cleaning (Vrouwenvelder et al., 2011). In this respect, experiments should be carried out on applying different cleaning steps and analysing the effectiveness of biomass removal for different feed spacer geometries. Again, as for the coating strategies, the feed spacer modification cannot prevent biofouling, but it can only reduce the impact of the accumulated biomass and enhance membrane module cleanability.

In conclusion, if biofouling cannot be avoided in the long run (Bucs et al., 2015), then biofouling control strategies should focus on delaying the biofilm formation, reducing its impact on membrane performance and allowing biofilm removal by advanced cleaning strategies.

\subsection{Spiral wound membrane modules cleaning strategies}

In order to maintain a constant clean water recovery without compromising energy input, it is important to control fouling in the system. When performance declines membrane modules need to be chemically cleaned to maintain the plant operation. Curative cleaning is the 
conventional approach practiced for quite a few decades where chemicals are flushed into the system when there is a performance decline. Chemical cleaning broadly includes weakening of the biofilm matrix mostly by chemicals such chelating agents, detergents, bases, acids and enzymes and removal of the biofilm by mechanical forces such as rinsing with water or air (Cornelissen et al., 2007; Wibisono et al., 2015).

Most commonly a combination of acidic and/or basic (alkaline) chemicals are used to clean the membrane modules. Common acidic solutions ( $\mathrm{pH}$ 2) include hydrochloric acid, phosphoric acid, sodium hydrosulfate and sulfamic acid, while alkaline ( $\mathrm{pH} 12$ ) chemicals include sodium lauryl sulfate, sodium hydroxide, sodium ethylene diamine tetra acetic acid. Commercial cleaning agents are found to be more effective than conventional cleaning agents recommended by the membrane manufacturers in some cases (DOW, 2014).

Hydraulic cleaning is the most commonly used physical cleaning method wherein water is flushed through the system in forward or backward direction to remove the accumulated biomass and organic foulants. Forward flushing in fact can cause further biofouling as the biomass accumulated in the lead membrane is pushed to the ones downstream, where they form new biofilms almost instantly. Due to this reason, some plants perform a backwash by reversing the module, thereby reducing the chance of spreading the biomass to all the adjacent membrane modules (reference). Pneumatic cleaning refers to the use of air or gas mixed with water for flushing (air-water flushing). A series of experiments done by Cornelissen et al., shows promising results on pilot scale for the use of air/water flushing (Cornelissen et al., 2007; Wibisono et al., 2015, 2014). $\mathrm{CO}_{2}$ dissolved in water has proved to restore initial hydraulic resistance as well as visible reduction in biofouling (Ngene et al., 2010)(Ngene, Lammertink et al. 2010).

\section{Future research directions}

Experimental and modelling results show that the same amount of biofilm impacts differently the membrane process performance (i.e., the feed channel pressure drop and flux)(Bucs et al., 2016, 2014a). It was hypothesized that the biofilm location (membrane and spacer), biofilm geometrical properties (porosity, thickness, and roughness), biofilm mechanical characteristics (rigidity, viscoelasticity, and density) and its hydraulic properties (permeability) all contribute to the membrane process performance decline. Therefore, future studies should focus on: (i) biofilm structural characterization; (ii) understanding to what extent biofilm properties affect membrane filtration performance, (iii) developing methods to engineer biofilm properties such 
that biofouling would have only a low or delayed impact on the filtration process and biomass should be easily removable.

\subsection{Biofilm structural characterization}

Traditionally biofilm characterization is carried out by microscopy methods. However, sample preparation for Scanning Electron Microscopy (SEM) may affect the biofilm structure and the method is off-line. Therefore, in-situ imaging methods should be pursued. Confocal laser scanning microscopy (CLSM) can be applied on-line or off-line, maintaining the biofilm structure. However, the sample must be fluorescent (either auto-fluorescent or stained), which may influence the biofilm behaviour and structure. In addition, the size of the observed area with CLSM is rather small for this application. Computed Tomography (CT) can acquire threedimensional images of the biofilm surface attached to support materials with highly complex geometry, but contrast agents must be added (Davit et al., 2011). There is a clear need for further development of in-situ, online characterization methods of the biofouling layer under representative conditions for practice.

Recent progress in the three-dimensional in-situ non-destructive biofilm imaging has been achieved by Magnetic Resonance Imaging (MRI) (Fridjonsson et al., 2015; Graf von der Schulenburg et al., 2008) and Optical Coherence Tomography (OCT) (Blauert et al., 2015; Wagner et al., 2010; West et al., 2015). MRI imaging can cover large areas (a few $\mathrm{cm}^{2}$ ) of actual spiral wound membrane modules, and evaluate the biofilm distribution and preferential flow channel formation over the module length (Vrouwenvelder et al., 2010).

Optical coherence tomography can be used to investigate biofilm formation in-situ and without staining. The rationale to focus on OCT in this paper is because this the only technique able for direct, in situ, non-destructive and high resolution imaging of biofilms in membrane fouling simulators. OCT has been used to study the change in performance parameters (e.g., feed channel pressure drop, flux) using different types of membranes (RO, UF, MF) (Derlon et al., 2013; Dreszer et al., 2014; Fortunato et al., 2017, 2016; West et al., 2015). 


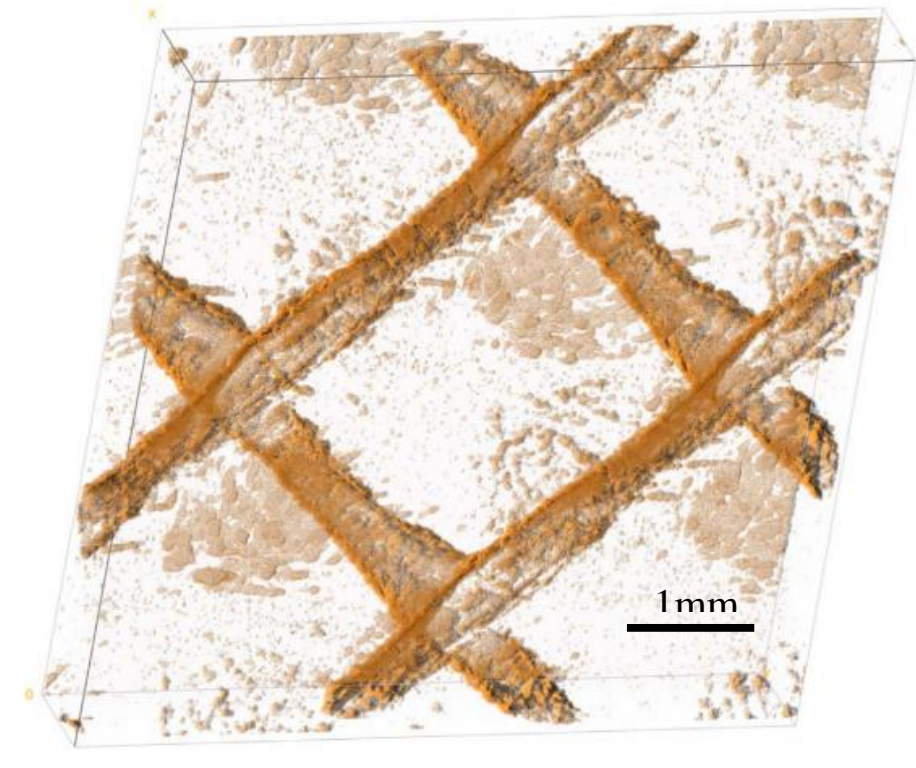

(a)

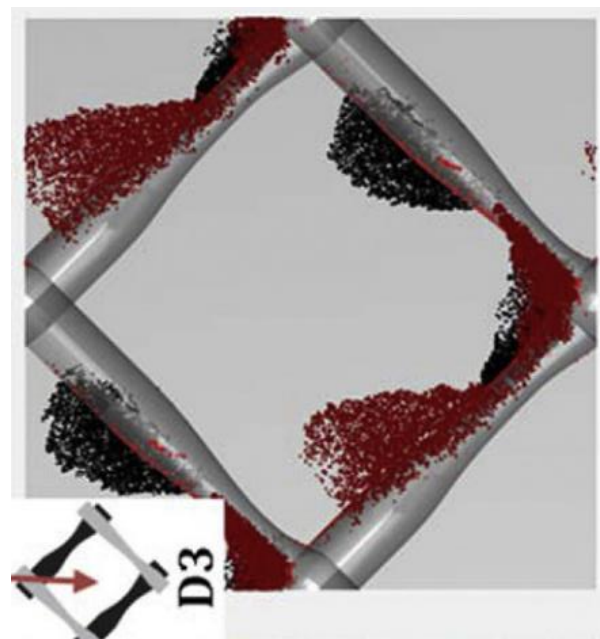

(b)

Figure 1: (a) Three-dimensional OCT image with biomass (brown colour), feed spacer, membrane and cover glass. Adapted from Fortunato et al. (2017). (b) Three-dimensional simulation of particle deposition on top (red) and bottom (black) membranes, in a spacer-filled feed channel, showing fouling patterns similar to those experimentally observed. Adapted from Radu et al. (2014).

The main advantages of the OCT technique are: (i) it enables three-dimensional observation and quantification of the biofilm over a large area (millimetres); (ii) it is totally non-invasive, requires no staining and can be performed during the operation of a lab-scale membrane setup and (iii) biofilm formation can be observed in time. A recent OCT study (Fortunato et al., 2017) clearly showing specific and reproducible locations of biofilm growth in a spacer-filled channel with permeation is represented in Figure 1. Moreover, this technique can supply valuable data to be used in conjunction with numerical modelling of fluid dynamics and biofilm formation, as also shown in Figure 1.

\subsection{Biofilm mechanical characterization}

Mechanical biofilm properties should also be determined, as these can be strongly connected with the rate of biofilm removal (e.g., biofilm detachment) and thus with the efficiency of several chemical or mechanical treatments. A suite of (classical) methods, such as rheology, nuclear magnetic resonance (NMR) imaging, and atomic force microscopy (AFM) techniques, and advances in instrumentation for determining biofilm mechanical properties has broadened the technological advances in instrumentation and interactions between multiple disciplines that have broadened the spectrum of methods available to conduct studies on biofilm mechanical 
properties (Billings et al., 2015). Biofilm elasticity modulus and Poisson ratio could be estimated from real-time cross sectional OCT scans of biofilms (Blauert et al., 2015). However, the mechanical properties of biofilms should be evaluated in relation to their hydraulic properties (e.g., permeability) and with membrane system performance decline, all in different membrane operating conditions. Three-dimensional biofilm scans can be numerically processed to extract structural (morphology) parameters such as: biovolume, biofilm thickness, roughness and porosity (Fortunato et al., 2016). Hardly accessible mechanical properties can be evaluated with time-dependent OCT scans, which is a clear advantage of this technique. For example, biofilm rigidity, viscoelasticity and density should be measured, as these strongly correlate with biofilm detachment and therefore with cleanability of the membrane system (Billings et al., 2015; Dreszer et al., 2014; Hohne et al., 2009; Houari et al., 2008; Towler et al., 2003; Valladares Linares et al., 2015). Biofilm response under operational changes can be immediately observed, such as compaction with increased water flux (Figure 2).

Precompaction

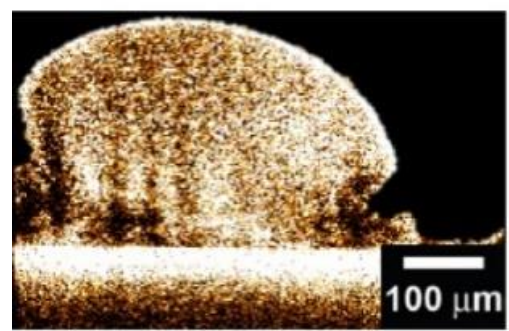

\section{Compaction}
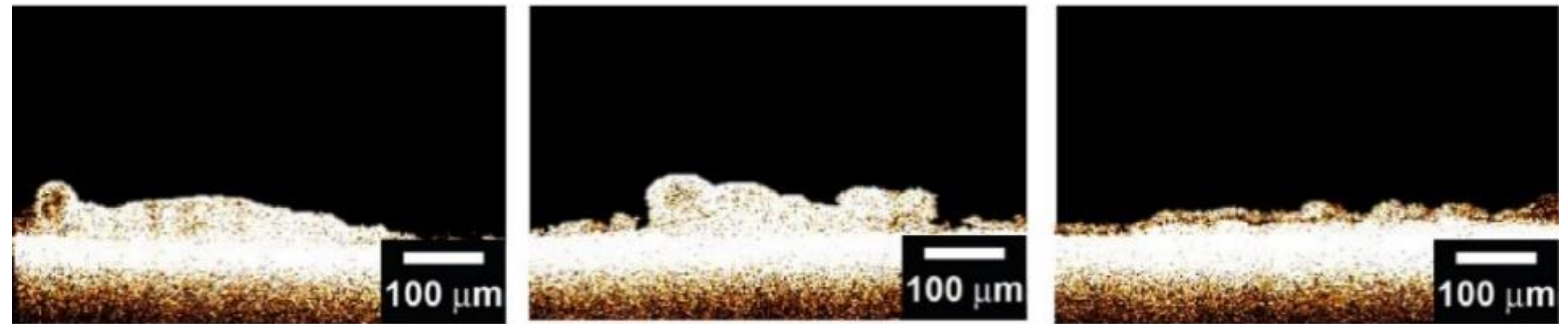

Relaxation
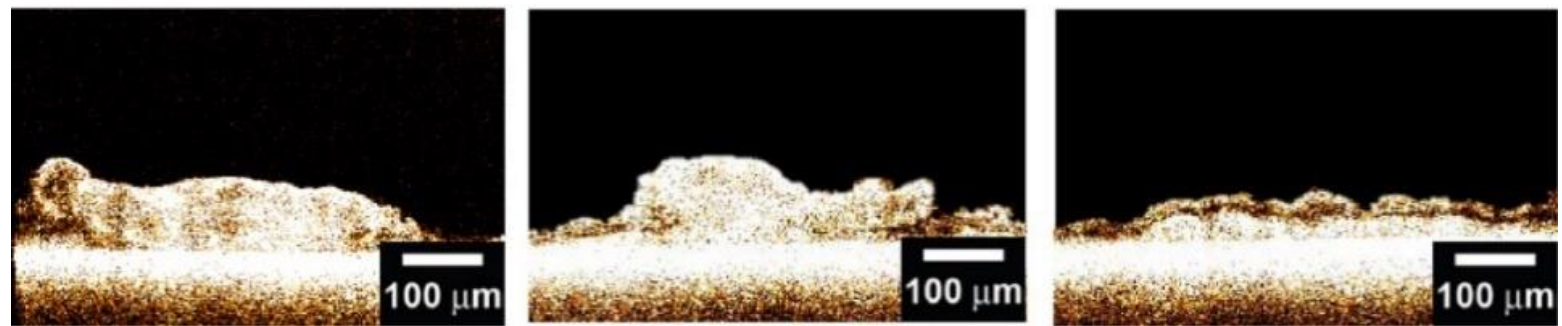

Figure 2: Optical coherence tomography observations of the biofilm at different locations in the flow channel: (top) initially; (middle) compacted by flux increase; (bottom) relaxed to the initial permeate flux. Figure from: Valladares Linares et al. (2016). 
In this way, the behaviour of biofilms formed in different membrane filtration processes (i.e., reversed osmosis versus forward osmosis) can be evaluated. Knowledge on biofilms formed in different membrane systems varying in driving force may lead to the development of more effective biofouling control strategies.
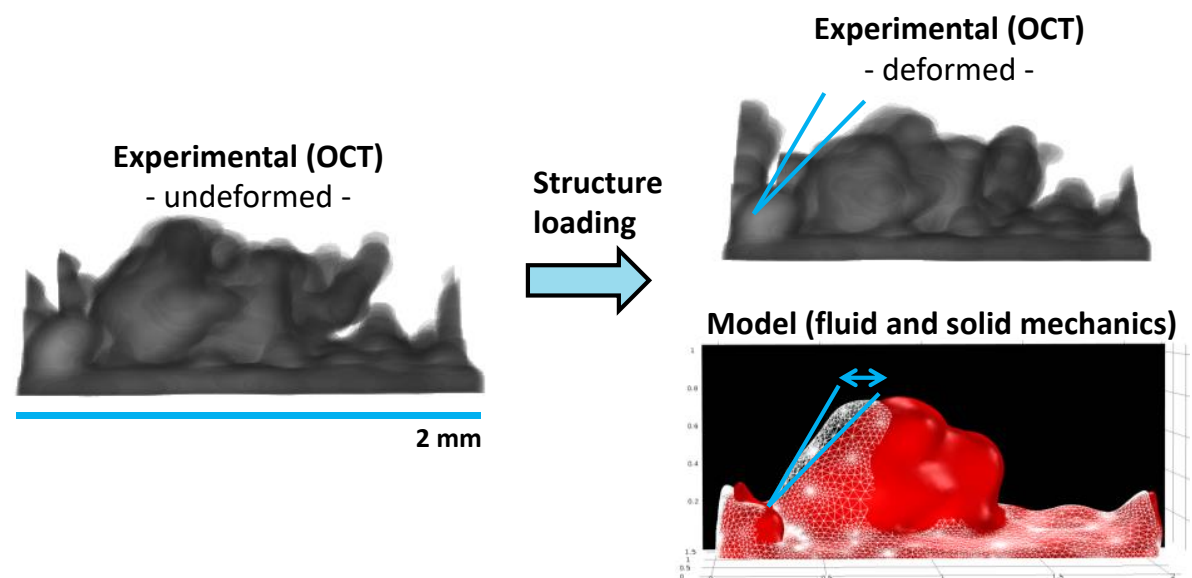

Figure 3: Determination of the elastic modulus by using deformed and undeformed biofilm geometry from optical coherence tomography (Blauert et al., 2015) in a fluid-structure interaction numerical model (C. Picioreanu, unpublished).

Furthermore, the determined biofilm properties can provide input values in numerical models, which can be used to increase the understanding and to predict biofouling effects on membrane process performance. Based on the OCT scans, the biofilm mechanical properties can be individually evaluated by computational models, which would be advantageous when decoupling effects is not possible experimentally (Figure ).

\subsection{Biofouling mitigation strategies}

Membrane and spacer surface modification. It is believed that understanding the early stages of biofilm formation could lead to the development of "antifouling" coatings for membrane and spacer surfaces. However, until now, no reported coating could prevent biofilm formation on long term. We believe therefore that the focus of research should change from biofouling prevention, to find ways to restrict biofilm formation and to facilitate biofilm removal.

New spacer designs. Based on the current literature, the spacer geometry appear to play an important role on biofilm formation and, most probably, also on the efficient biofilm removal from the membrane system (Siddiqui et al., 2017a, 2016). A possible optimization loop leading to the design of better spacers is proposed in Figure 4. Several commercial feed spacers can be screened for their hydrodynamics, mass transport and fouling properties. An accurate geometry of a selected spacer can be obtained by X-ray computed tomography (CT scanning step 
(Haaksman et al., 2017)). This geometry is imported in a computer aided design (CAD) package and a virtual three-dimensional (3D) spacer model can be generated. This virtual model is furthermore altered so that a redesigned spacer geometry can be proposed, according to preexisting knowledge on how different spacer elements contribute to membrane performance. The new spacer design is first evaluated numerically for hydrodynamics and mass transfer properties (e.g., (Haaksman et al., 2017)). Based on the numerical simulations, the spacer geometry could be further improved. Once the simulations indicate a superior spacer, a prototype will be manufactured by three-dimensional printing (Siddiqui et al., 2016). The prototype is further evaluated in lab-scale experimental setups (e.g., in membrane fouling simulators) for hydrodynamics (pressure drop and permeation), mass transfer (concentration polarization), fouling behaviour (biofouling, scaling) and associated cleanability. If the labscale tests indicate a successful spacer design, pilot scale experiments (spiral wound membrane module) should be carried out and eventually the spacer could be commercialized. If the tests reveal that the spacer needs further improvement, a new virtual design should be proposed and the testing cycle continues (Figure 4 ). 


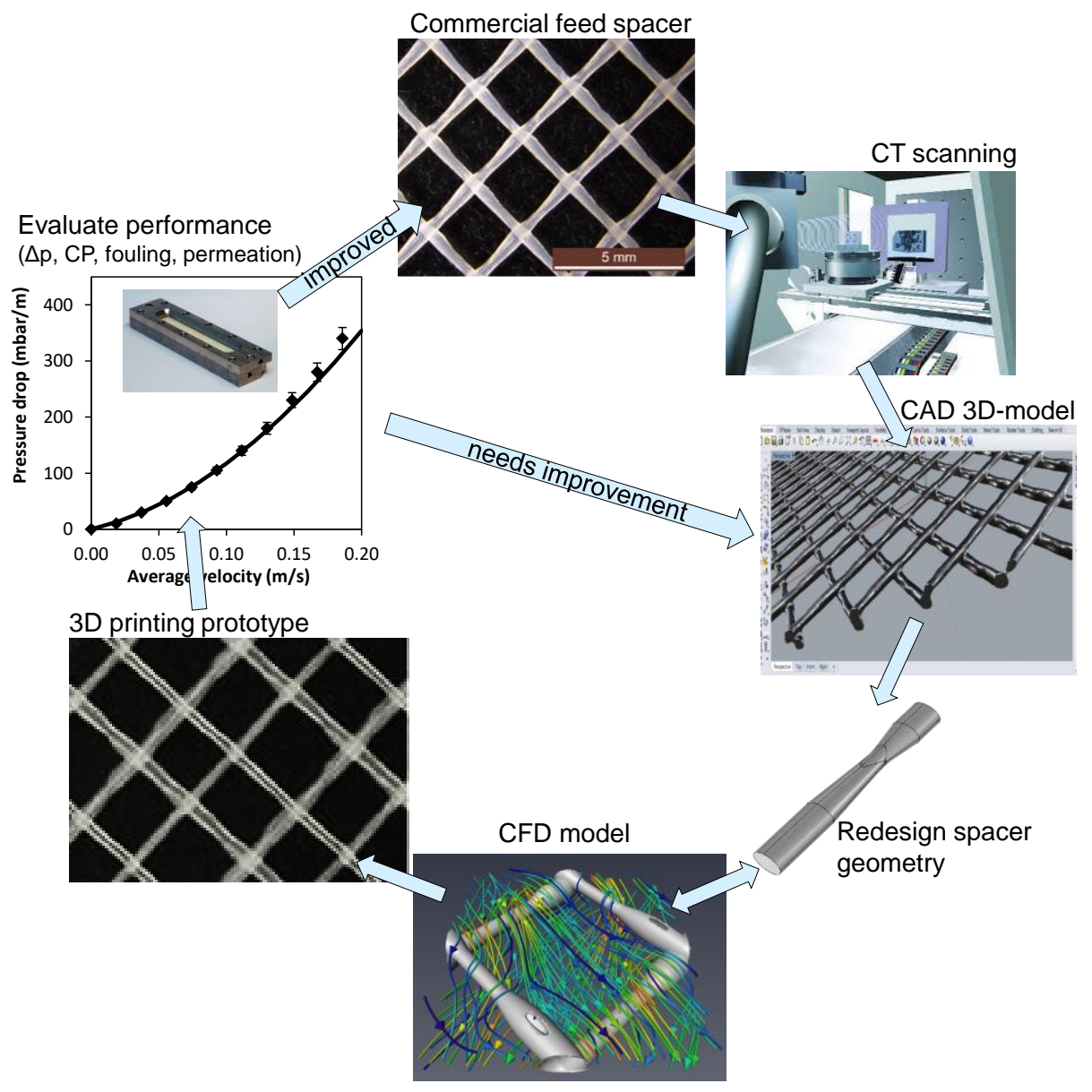

Figure 4: Proposed steps in the development of improved spacers for membrane filtration systems involving, 3D printing, CT scanning and numerical modeling in conjunction with experimental testing.

Numerical evaluation. For an accurate assessment of the virtual design of the feed spacer, progress in numerical modelling has to be achieved in several areas. The computational fluid dynamics would need to include, beside the laminar steady flow (e.g., Picioreanu et al., 2009; Bucs et al., 2014a) also unsteady and time-dependent flow. As shown by Bucs et al. (2015) at velocities used in practice in RO systems the flow begins to develop unsteady behaviour. Especially under fouling conditions the flow channel porosity changes which may lead to flow instability. This requires the use of more demanding computational fluid dynamics methods, which can represent both steady and unsteady flows (Fortunato et al., 2017; Koutsou et al., 2007). Another important aspect to be considered in numerical simulations is the representativeness of the spacer geometry. Picioreanu et al. (2009) showed that the simplification of the spacer geometry in numerical models (e.g., cylindrical spacer filaments with uniform diameters) leads to non-representative hydrodynamics, therefore not desirable when simulating spacers used in practice. Moreover, since the feed spacer geometries used in 
practice are not completely symmetrical, the orientation of the feed spacer versus the main flow direction has to be considered as well in numerical models (Radu et al., 2014).

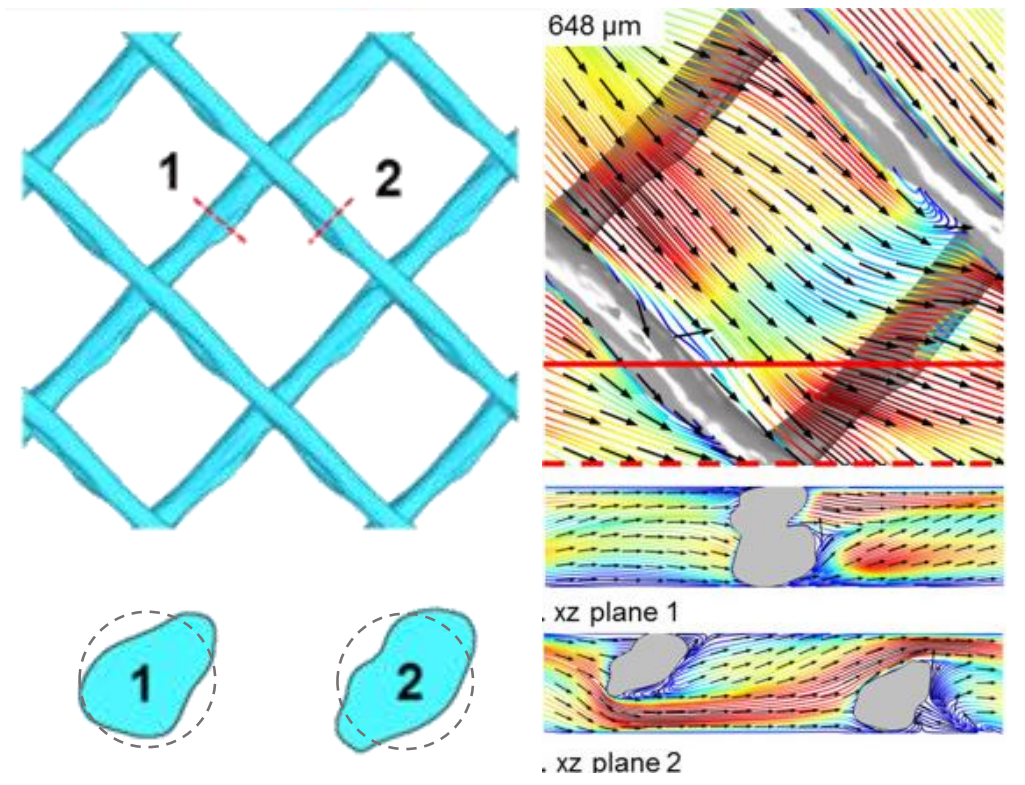

(a)

(b)

Figure 5: (a) Top view and cross sections of a spacer geometry scanned by X-ray computed tomography (CT); (b) Simulated water flow in laminar steady conditions, with streamlines showing flow velocity in a colour scale (red: high and blue: low velocity). Figure adapted from Haaksman et al. (2017). The dashed-line circles in (a) represent cross-sections as they would appear from top-view microscopic observation assuming perfectly cylindrical spacer fibres.

As the spacer fibres in practice do not have a perfectly circular cross-section and their diameter is variable along the fibres (Haaksman et al., 2017), the simplified spacer geometries (e.g., cylinders) may not be sufficient to characterize the hydraulic impact of the virtual spacer (Figure 5). Therefore, spacers geometries derived from X-ray computed tomography scans should be used in numerical simulations.

In summary, details of spacer geometry and flow conditions are important for accurate numerical simulations, and proper results can only be obtained if actual feed spacer geometries are used. We believe that the proposed development cycle (Figure 4) can improve the rational design of spacers with a lower fouling potential, higher cleanability and thereby a better operational effectiveness of the whole membrane process.

Membrane cleaning strategies. Evaluations of new cleaning strategies for biofilm removal are still scarcely reported. By understanding how the biofilm forms and reacts to operation conditions, more effective cleaning methods can be proposed. With advanced imaging 
techniques like optical coherence tomography the immediate impact of various physical and chemical agents on biofilms could be assessed. Examples of physical cleaning methods include: variation in shear by pulsating flow (Radu et al., 2012), air sparging (Cornelissen et al., 2007), back-washing and osmotic shock (Mi and Elimelech, 2010). Although chemical cleaning is widely used in industrial applications, current cleaning strategies inactivate most biofilm bacterial cells without removing the biofilm from the membrane module. Rather than inactivation of the bacterial cells, the focus for chemical cleaning should be on lysing the natural polymeric matrix, followed by removal of the biofilm (Bereschenko et al., 2011).

\section{Conclusions}

1. Biofouling cannot be avoided, thus control strategies should focus on: (i) delayed biofilm formation, (ii) reduced or delayed impact of accumulated biofilm on performance and (iii) biofilm removal by advanced cleaning strategies.

2. Controlling biofouling and biofilm formation requires better understanding of biofilm development under hydraulic conditions and over time periods representative in practice.

3. Novel imaging and analytical methods allow to study biofilm formation on-line and insitu, and are able to deliver information on the biofilm morphology and mechanical properties.

4. By understanding biofilm mechanics and its interactions with the water flow, novel control and engineering strategies can be developed to mitigate biofouling in spiral wound membrane systems.

5. Cleaning strategies should focus on lysing and removal of biofilms, rather than on mechanical destruction or bacterial cell inactivation.

6. Computational methods should be improved to: (i) represent time-dependent and unsteady flows; (ii) represent the fluid-biofilm interaction effects on permeation, pressure drop and biofilm removal; (iii) describe more accurately the spacer geometry.

\section{Acknowledgements}

The research reported in this publication was supported by funding from King Abdullah University of Science and Technology (KAUST). 


\section{Reference}

Alawadhi, A.A., 1997. Pretreatment plant design - Key to a successful reverse osmosis desalination plant. Desalination 110, 1-10. doi:10.1016/S0011-9164(97)00079-9

Amokrane, M., Sadaoui, D., Koutsou, C.P., Karabelas, A.J., Dudeck, M., 2015. A study of flow field and concentration polarization evolution in membrane channels with twodimensional spacers during water desalination. J. Memb. Sci. 477, 139-150. doi:10.1016/j.memsci.2014.11.029

Araújo, P.A., Miller, D.J., Correia, P.B., van Loosdrecht, M.C.M., Kruithof, J.C., Freeman, B.D., Paul, D.R., Vrouwenvelder, J.S., 2012. Impact of feed spacer and membrane modification by hydrophilic, bactericidal and biocidal coating on biofouling control. Desalination 295, 1-10. doi:10.1016/j.desal.2012.02.026

Asatekin, A., Olivetti, E.A., Mayes, A.M., 2009. Fouling resistant, high flux nanofiltration membranes from polyacrylonitrile-graft-poly(ethylene oxide). J. Memb. Sci. 332, 6-12. doi:10.1016/j.memsci.2009.01.029

Baker, J., Stephenson, T., Dard, S., Cote, P., 1995. Characterisation of fouling of nanofiltration membranes used to treat surface waters. Environ. Technol. 16, 977-985. doi:10.1080/09593331608616335

Bereschenko, L.A., Prummel, H., Euverink, G.J.W., Stams, A.J.M., van Loosdrecht, M.C.M., 2011. Effect of conventional chemical treatment on the microbial population in a biofouling layer of reverse osmosis systems. Water Res. 45, 405-416. doi:10.1016/j.watres.2010.07.058

Bertheas, U., Majamaa, K., Arzu, A., Pahnke, R., 2009. Use of DBNPA to control biofouling in RO systems. Desalin. Water Treat. 3, 175-178. doi:10.5004/dwt.2009.457

Billings, N., Birjiniuk, A., Samad, T.S., Doyle, P.S., Ribbeck, K., 2015. Material properties of biofilms-a review of methods for understanding permeability and mechanics. Rep. Prog. Phys. doi:10.1088/0034-4885/78/3/036601

Blauert, F., Horn, H., Wagner, M., 2015. Time-resolved biofilm deformation measurements using optical coherence tomography. Biotechnol. Bioeng. 112, 1893-1905. doi:10.1002/bit.25590

Brzozowska, A.M., Spruijt, E., de Keizer, A., Cohen Stuart, M.A., Norde, W., 2011. On the stability of the polymer brushes formed by adsorption of ionomer complexes on hydrophilic and hydrophobic surfaces. J. Colloid Interface Sci. 353, 380-91. doi:10.1016/j.jcis.2010.09.074

Bucs, S.S., Linares, R.V., Farhat, N., Matin, A., Khan, Z., Van Loosdrecht, M.C.M., Yang, R., Wang, M., Gleason, K.K., Kruithof, J.C., Vrouwenvelder, J.S., 2017. Coating of reverse osmosis membranes with amphiphilic copolymers for biofouling control. Desalin. Water Treat. 68. doi:10.5004/dwt.2017.20369

Bucs, S.S., Linares, R.V., Marston, J.O., Radu, A.I., Vrouwenvelder, J.S., Picioreanu, C., 2015. Experimental and numerical characterization of the water flow in spacer-filled channels of spiral-wound membranes. Water Res. 87, 299-310. doi:10.1016/j.watres.2015.09.036

Bucs, S.S., Radu, A.I., Lavric, V., Vrouwenvelder, J.S., Picioreanu, C., 2014a. Effect of different commercial feed spacers on biofouling of reverse osmosis membrane systems: 
A numerical study. Desalination 343, 26-37. doi:10.1016/j.desal.2013.11.007

Bucs, S.S., Valladares Linares, R., van Loosdrecht, M.C.M., Kruithof, J.C., Vrouwenvelder, J.S., 2014b. Impact of organic nutrient load on biomass accumulation, feed channel pressure drop increase and permeate flux decline in membrane systems. Water Res. 67, 227-42. doi:10.1016/j.watres.2014.09.005

Bucs, S.S., Valladares Linares, R., Vrouwenvelder, J.S., Picioreanu, C., 2016. Biofouling in forward osmosis systems: An experimental and numerical study. Water Res. 106. doi:10.1016/j.watres.2016.09.031

Chinu, K.J., Johir, A.H., Vigneswaran, S., Shon, H.K., Kandasamy, J., 2009. Biofilter as pretreatment to membrane based desalination: Evaluation in terms of fouling index. Desalination 247, 77-84. doi:10.1016/j.desal.2008.12.014

Chua, K.T., Hawlader, M.N.A., Malek, A., 2003. Pretreatment of seawater: Results of pilot trials in Singapore. Desalination 159, 225-243. doi:10.1016/S0011-9164(03)90075-0

Cornelissen, E., Vrouwenvelder, J.S., Heijman, S., Viallefont, X., van der Kooij, D., Wessels, L.P., 2007. Periodic air/water cleaning for control of biofouling in spiral wound membrane elements. J. Memb. Sci. 287, 94-101. doi:10.1016/j.memsci.2006.10.023

Creber, S.A., Vrouwenvelder, J.S., van Loosdrecht, M.C.M., Johns, M.L., 2010. Chemical cleaning of biofouling in reverse osmosis membranes evaluated using magnetic resonance imaging. J. Memb. Sci. 362, 202-210. doi:10.1016/j.memsci.2010.06.052

Davit, Y., Iltis, G., Debenest, G., Veran-Tissoires, S., Wildenschild, D., Gerino, M., Quintard, M., 2011. Imaging biofilm in porous media using X-ray computed microtomography. J. Microsc. 242, 15-25. doi:10.1111/j.1365-2818.2010.03432.x

Derlon, N., Koch, N., Eugster, B., Posch, T., Pernthaler, J., Pronk, W., Morgenroth, E., 2013. Activity of metazoa governs biofilm structure formation and enhances permeate flux during Gravity-Driven Membrane (GDM) filtration. Water Res. 47, 2085-2095. doi:10.1016/j.watres.2013.01.033

Dobretsov, S., Teplitski, M., Paul, V., 2009. Mini-review: quorum sensing in the marine environment and its relationship to biofouling. Biofouling 25, 413-427. doi:10.1080/08927010902853516

DOW, 2014. DOW FILMTEC ${ }^{\mathrm{TM}}$ Membranes, Cleaning Procedures for DOW FILMTEC FT30 Elements.

Dreszer, C., Wexler, A.D.D., Drusová, S., Overdijk, T., Zwijnenburg, A., Flemming, H.-C.H.C., Kruithof, J.C.C., Vrouwenvelder, J.S.J.S., 2014. In-situ biofilm characterization in membrane systems using Optical Coherence Tomography: formation, structure, detachment and impact of flux change. Water Res. 67, 243-54. doi:10.1016/j.watres.2014.09.006

Flemming, H.-C., 2002. Biofouling in water systems--cases, causes and countermeasures. Appl. Microbiol. Biotechnol. 59, 629-40. doi:10.1007/s00253-002-1066-9

Flemming, H.-C., 1997. Reverse osmosis membrane biofouling. Exp. Therm. Fluid Sci. 14, 382-391. doi:10.1016/S0894-1777(96)00140-9

Fortunato, L., Bucs, S., Linares, R.V., Cali, C., Vrouwenvelder, J.S., Leiknes, T., 2016. Spatially-resolved in-situ quantification of biofouling using optical coherence 
tomography (OCT) and 3D image analysis in a spacer filled channel. J. Memb. Sci. in press, 673-681. doi:10.1016/j.memsci.2016.11.052

Fortunato, L., Qamar, A., Wang, Y., Jeong, S., Leiknes, T., 2017. In-situ assessment of biofilm formation in submerged membrane system using optical coherence tomography and computational fluid dynamics. J. Memb. Sci. 521, 84-94. doi:10.1016/j.memsci.2016.09.004

Fridjonsson, E.O., Vogt, S.J., Vrouwenvelder, J.S., Johns, M.L., 2015. Early non-destructive biofouling detection in spiral wound RO membranes using a mobile earth's field NMR. J. Memb. Sci. 489, 227-236. doi:10.1016/j.memsci.2015.03.088

Geraldes, V., Semião, V., Norberta Pinho, M., 2003. Hydrodynamics and concentration polarization in NF/RO spiral-wound modules with ladder-type spacers. Desalination 157, 395-402. doi:10.1016/S0011-9164(03)00422-3

Graf von der Schulenburg, D.A., Vrouwenvelder, J.S., Creber, S.A., van Loosdrecht, M.C.M., Johns, M.L., 2008. Nuclear magnetic resonance microscopy studies of membrane biofouling. J. Memb. Sci. 323, 37-44. doi:10.1016/j.memsci.2008.06.012

Gu, B., Adjiman, C.S., Xu, X.Y., 2017. The effect of feed spacer geometry on membrane performance and concentration polarisation based on 3D CFD simulations. J. Memb. Sci. 527, 78-91. doi:10.1016/j.memsci.2016.12.058

Gur-Reznik, S., Katz, I., Dosoretz, C.G., 2008. Removal of dissolved organic matter by granular-activated carbon adsorption as a pretreatment to reverse osmosis of membrane bioreactor effluents. Water Res. 42, 1595-1605. doi:10.1016/j.watres.2007.10.004

Haaksman, V.A., Siddiqui, A., Schellenberg, C., Kidwell, J., Vrouwenvelder, J.S., Picioreanu, C., 2017. Characterization of feed channel spacer performance using geometries obtained by X-ray computed tomography. J. Memb. Sci. 522, 124-139. doi:10.1016/j.memsci.2016.09.005

Hadidi, M., Zydney, A.L., 2014. Fouling behavior of zwitterionic membranes: Impact of electrostatic and hydrophobic interactions. J. Memb. Sci. 452, 97-103. doi:10.1016/j.memsci.2013.09.062

Herzberg, M., Elimelech, M., 2007. Biofouling of reverse osmosis membranes: Role of biofilm-enhanced osmotic pressure. J. Memb. Sci. 295, 11-20. doi:10.1016/j.memsci.2007.02.024

Hohne, D.N., Younger, J.G., Solomon, M.J., 2009. Flexible microfluidic device for mechanical property characterization of soft viscoelastic solids such as bacterial biofilms. Langmuir 25, 7743-7751. doi:10.1021/la803413x

Houari, A., Picard, J., Habarou, H., Galas, L., Vaudry, H., Heim, V., Di Martino, P., 2008. Rheology of biofilms formed at the surface of NF membranes in a drinking water production unit. Biofouling 24, 235-240. doi:10.1080/08927010802023764

Kang, G., Cao, Y., 2012. Development of antifouling reverse osmosis membranes for water treatment: A review. Water Res. 46, 584-600. doi:10.1016/j.watres.2011.11.041

Kim, I.C., Lee, K.H., 2006. Dyeing process wastewater treatment using fouling resistant nanofiltration and reverse osmosis membranes. Desalination 192, 246-251. doi:10.1016/j.desal.2005.05.030 
Koutsou, C.P., Karabelas, A.J., 2015. A novel retentate spacer geometry for improved spiral wound membrane (SWM) module performance. J. Memb. Sci. 488, 129-142. doi:10.1016/j.memsci.2015.03.064

Koutsou, C.P., Karabelas, A.J., 2010. Towards optimization of spacer geometrical characteristics for spiral wound membrane modules. Desalin. Water Treat. 18, 139-150. doi:10.5004/dwt.2010.1382

Koutsou, C.P., Yiantsios, S.G., Karabelas, A.J., 2009. A numerical and experimental study of mass transfer in spacer-filled channels: Effects of spacer geometrical characteristics and Schmidt number. J. Memb. Sci. 326, 234-251. doi:10.1016/j.memsci.2008.10.007

Koutsou, C.P.P., Yiantsios, S.G.G., Karabelas, A.J.J., 2007. Direct numerical simulation of flow in spacer-filled channels: Effect of spacer geometrical characteristics. J. Memb. Sci. 291, 53-69. doi:10.1016/j.memsci.2006.12.032

Lattemann, S., Kennedy, M.D., Schippers, J.C., Amy, G., 2010. Chapter 2 Global Desalination Situation. Sustain. Sci. Eng. doi:10.1016/S1871-2711(09)00202-5

Louie, J.S., Pinnau, I., Ciobanu, I., Ishida, K.P., Ng, A., Reinhard, M., 2006. Effects of polyether-polyamide block copolymer coating on performance and fouling of reverse osmosis membranes. J. Memb. Sci. 280, 762-770. doi:10.1016/j.memsci.2006.02.041

Louie, J.S., Pinnau, I., Reinhard, M., 2011. Effects of surface coating process conditions on the water permeation and salt rejection properties of composite polyamide reverse osmosis membranes. J. Memb. Sci. 367, 249-255. doi:10.1016/j.memsci.2010.10.067

Matin, A., Shafi, H.Z., Khan, Z., Khaled, M., Yang, R., Gleason, K., Rehman, F., 2014. Surface modification of seawater desalination reverse osmosis membranes: Characterization studies \& performance evaluation. Desalination 343, 128-139. doi:10.1016/j.desal.2013.10.023

Meier, J., Melin, T., 2005. Wastewater reclamation by the PAC-NF process. Desalination 178, 27-40. doi:10.1016/j.desal.2004.12.015

Mi, B., Elimelech, M., 2010. Organic fouling of forward osmosis membranes: Fouling reversibility and cleaning without chemical reagents. J. Memb. Sci. 348, 337-345. doi:10.1016/j.memsci.2009.11.021

Miller, D.J., Araújo, P.A., Correia, P.B., Ramsey, M.M., Kruithof, J.C., van Loosdrecht, M.C.M., Freeman, B.D., Paul, D.R., Whiteley, M., Vrouwenvelder, J.S., 2012. Short-term adhesion and long-term biofouling testing of polydopamine and poly(ethylene glycol) surface modifications of membranes and feed spacers for biofouling control. Water Res. 46, 3737-53. doi:10.1016/j.watres.2012.03.058

Ngene, I.S., Lammertink, R.G.H., Kemperman, A.J.B., Van De Ven, W.J.C., Wessels, L.P., Wessling, M., Van Der Meer, W.G.J., 2010. CO2nucleation in membrane spacer channels remove biofilms and fouling deposits. Ind. Eng. Chem. Res. 49, 10034-10039. doi:10.1021/ie1011245

Nguyen, T., Roddick, F.A., Fan, L., 2012. Biofouling of water treatment membranes: a review of the underlying causes, monitoring techniques and control measures. Membranes (Basel). 2, 804-40. doi:10.3390/membranes2040804

Ostuni, E., Chapman, R.G., Holmlin, R.E., Takayama, S., Whitesides, G.M., 2001. A survey 
of structure-property relationships of surfaces that resist the adsorption of protein. Langmuir. doi:10.1021/la010384m

Pankratz, T., 2012. Water Desalination Report. Desalination 48, 1-4.

Picioreanu, C., Vrouwenvelder, J.S., van Loosdrecht, M.C.M., 2009. Three-dimensional modeling of biofouling and fluid dynamics in feed spacer channels of membrane devices. J. Memb. Sci. 345, 340-354. doi:10.1016/j.memsci.2009.09.024

Prihasto, N., Liu, Q.F., Kim, S.H., 2009. Pre-treatment strategies for seawater desalination by reverse osmosis system. Desalination 249, 308-316. doi:10.1016/j.desal.2008.09.010

Radu, A.I., Bergwerff, L., van Loosdrecht, M.C.M., Picioreanu, C., 2015. Combined biofouling and scaling in membrane feed channels: a new modeling approach. Biofouling 31, 83100. doi:10.1080/08927014.2014.996750

Radu, A.I., van Steen, M.S.H., Vrouwenvelder, J.S., van Loosdrecht, M.C.M., Picioreanu, C., 2014. Spacer geometry and particle deposition in spiral wound membrane feed channels. Water Res. 64, 160-176. doi:10.1016/j.watres.2014.06.040

Radu, A.I., Vrouwenvelder, J.S., van Loosdrecht, M.C.M., Picioreanu, C., 2012. REMOVED: Modeling Biofouling, Scaling and Combined Fouling in Reverse Osmosis Membrane Devices. Procedia Eng. 44, 341-342. doi:http://dx.doi.org/10.1016/j.proeng.2012.08.409

Ronen, A., Lerman, S., Ramon, G.Z., Dosoretz, C.G., 2015. Experimental characterization and numerical simulation of the anti-biofuling activity of nanosilver-modified feed spacers in membrane filtration. J. Memb. Sci. 475, 320-329. doi:10.1016/j.memsci.2014.10.042

Sagle, A.C., Van Wagner, E.M., Ju, H., McCloskey, B.D., Freeman, B.D., Sharma, M.M., 2009. PEG-coated reverse osmosis membranes: Desalination properties and fouling resistance. J. Memb. Sci. 340, 92-108. doi:10.1016/j.memsci.2009.05.013

Schwinge, J., Neal, P.R., Wiley, D.E., Fletcher, D.F., Fane, A.G., 2004. Spiral wound modules and spacers. J. Memb. Sci. 242, 129-153. doi:10.1016/j.memsci.2003.09.031

Siddiqui, A., Farhat, N., Bucs, S.S., Linares, R.V., Picioreanu, C., Kruithof, J.C., van Loosdrecht, M.C.M., Kidwell, J., Vrouwenvelder, J.S., 2016. Development and characterization of 3D-printed feed spacers for spiral wound membrane systems. Water Res. 91, 55-67. doi:10.1016/j.watres.2015.12.052

Siddiqui, A., Lehmann, S., Bucs, S.S., Fresquet, M., Fel, L., Prest, E.I.E.C., Ogier, J., Schellenberg, C., van Loosdrecht, M.C.M., Kruithof, J.C., Vrouwenvelder, J.S., 2017a. Predicting the impact of feed spacer modification on biofouling by hydraulic characterization and biofouling studies in membrane fouling simulators. Water Res. 110. doi:10.1016/j.watres.2016.12.034

Siddiqui, A., Pinel, I., Prest, E.I., Bucs, S.S., van Loosdrecht, M.C.M., Kruithof, J.C., Vrouwenvelder, J.S., 2017b. Application of DBNPA dosage for biofouling control in spiral wound membrane systems. Desalin. Water Treat. 68. doi:10.5004/dwt.2017.20370

Tang, C.Y., Kwon, Y.-N., Leckie, J.O., 2009. Effect of membrane chemistry and coating layer on physiochemical properties of thin film composite polyamide RO and NF membranes. Desalination 242, 168-182. doi:10.1016/j.desal.2008.04.004

Towler, B.W., Rupp, C.J., Cunningham, A.L.B., Stoodley, P., 2003. Viscoelastic Properties of a Mixed Culture Biofilm from Rheometer Creep Analysis. Biofouling 19, 279-285. 


\section{doi:10.1080/0892701031000152470}

Tran, T., Bolto, B., Gray, S., Hoang, M., Ostarcevic, E., 2007. An autopsy study of a fouled reverse osmosis membrane element used in a brackish water treatment plant. Water Res. 41, 3915-3923. doi:10.1016/j.watres.2007.06.008

UNDP, 2006. Human Development Report 2006, Journal of Government Information. doi:10.1016/S1352-0237(02)00387-8

Valladares Linares, R., Wexler, A.D., Bucs, S.S., Dreszer, C., Zwijnenburg, A., Flemming, H.C., Kruithof, J.C., Vrouwenvelder, J.S., 2015. Compaction and relaxation of biofilms. Desalin. Water Treat. 1-13. doi:10.1080/19443994.2015.1057036

Van Geluwe, S., Vinckier, C., Braeken, L., Van der Bruggen, B., 2011. Ozone oxidation of nanofiltration concentrates alleviates membrane fouling in drinking water industry. J. Memb. Sci. 378, 128-137. doi:10.1016/j.memsci.2011.04.059

van Loosdrecht, M.C.M., Lyklema, J., Norde, W., Zehnder, A.J.B., 1989. Bacterial adhesion: A physicochemical approach. Microb. Ecol. 17, 1-15. doi:10.1007/BF02025589

Venault, A., Liu, Y.H., Wu, J.R., Yang, H.S., Chang, Y., Lai, J.Y., Aimar, P., 2014. Lowbiofouling membranes prepared by liquid-induced phase separation of the PVDF/polystyrene-b-poly (ethylene glycol) methacrylate blend. J. Memb. Sci. 450, 340350. doi:10.1016/j.memsci.2013.09.004

Vörösmarty, C.J., Green, P., Salisbury, J., Lammers, R.B., 2000. Global water resources: vulnerability from climate change and population growth. Science (80-. ). 289, 284-288. doi:10.1126/science.289.5477.284

Vrouwenvelder, J.S., Graf von der Schulenburg, D.A., Kruithof, J.C.C., Johns, M.L.L., van Loosdrecht, M.C.M., 2009a. Biofouling of spiral-wound nanofiltration and reverse osmosis membranes: a feed spacer problem. Water Res. 43, 583-94. doi:10.1016/j.watres.2008.11.019

Vrouwenvelder, J.S., Hinrichs, C., van der Meer, W.G.J., van Loosdrecht, M.C.M., Kruithof, J.C., 2009b. Pressure drop increase by biofilm accumulation in spiral wound RO and NF membrane systems: role of substrate concentration, flow velocity, substrate load and flow direction. Biofouling 25, 543-555. doi:10.1080/08927010902972225

Vrouwenvelder, J.S., Manolarakis, S.A., Veenendaal, H.R., van der Kooij, D., 2000. Biofouling potential of chemicals used for scale control in RO and NF membranes. Desalination 132, 1-10. doi:10.1016/S0011-9164(00)00129-6

Vrouwenvelder, J.S., Picioreanu, C., Kruithof, J.C.C., van Loosdrecht, M.C.M., 2010. Biofouling in spiral wound membrane systems: Three-dimensional CFD model based evaluation of experimental data. J. Memb. Sci. 346, 71-85. doi:10.1016/j.memsci.2009.09.025

Vrouwenvelder, J.S., Van Loosdrecht, M.C.M., Kruithof, J.C., 2011. A novel scenario for biofouling control of spiral wound membrane systems. Water Res. 45, 3890-8. doi:10.1016/j.watres.2011.04.046

Wagner, M., Taherzadeh, D., Haisch, C., Horn, H., 2010. Investigation of the mesoscale structure and volumetric features of biofilms using optical coherence tomography. Biotechnol. Bioeng. 107, 844-853. doi:10.1002/bit.22864 
Wang, C., Such, G.K., Widjaya, A., Lomas, H., Stevens, G., Caruso, F., Kentish, S.E., 2012. Click poly(ethylene glycol) multilayers on RO membranes: Fouling reduction and membrane characterization. J. Memb. Sci. 409-410, 9-15. doi:10.1016/j.memsci.2012.02.049

West, S., Wagner, M., Engelke, C., Horn, H., 2015. Optical coherence tomography for the in situ three-dimensional visualization and quantification of feed spacer channel fouling in reverse osmosis membrane modules. J. Memb. Sci. 498, 345-352. doi:10.1016/j.memsci.2015.09.047

Wibisono, Y., Cornelissen, E.R., Kemperman, A.J.B., van der Meer, W.G.J., Nijmeijer, K., 2014. Two-phase flow in membrane processes: A technology with a future. J. Memb. Sci. 453, 566-602. doi:http://dx.doi.org/10.1016/j.memsci.2013.10.072

Wibisono, Y., El Obied, K.E., Cornelissen, E.R., Kemperman, a. J.B., Nijmeijer, K., 2015. Biofouling removal in spiral-wound nanofiltration elements using two-phase flow cleaning. J. Memb. Sci. 475, 131-146. doi:10.1016/j.memsci.2014.10.016

Yu, W., Brown, M., Graham, N.J.D., 2016. Prevention of PVDF ultrafiltration membrane fouling by coating $\mathrm{MnO} 2$ nanoparticles with ozonation. Sci. Rep. 6, 30144. doi:10.1038/srep30144

Zhao, D., Yu, S., 2015. A review of recent advance in fouling mitigation of NF/RO membranes in water treatment: pretreatment, membrane modification, and chemical cleaning. Desalin. Water Treat. 55, 870-891. doi:10.1080/19443994.2014.928804

Zhao, Y.-H., Zhu, B.-K., Kong, L., Xu, Y.-Y., 2007. Improving Hydrophilicity and Protein Resistance of Poly(vinylidene fluoride) Membranes by Blending with Amphiphilic Hyperbranched-Star Polymer. Langmuir 23, 5779-5786. doi:10.1021/la070139o

Zhao, Y.H., Wee, K.H., Bai, R., 2010. Highly hydrophilic and low-protein-fouling polypropylene membrane prepared by surface modification with sulfobetaine-based zwitterionic polymer through a combined surface polymerization method. J. Memb. Sci. 362, 326-333. doi:10.1016/j.memsci.2010.06.037

Zhu, L.-P., Xu, Y.-Y., Wei, X.-Z., Zhu, B.-K., 2009. Hydrophilic modification of poly(phthalazine ether sulfone ketone) ultrafiltration membranes by the surface immobilization of poly(ethylene glycol) acrylates. Desalination 242, 96-109. doi:10.1016/j.desal.2008.03.034 